\title{
Size and shape of airborne asbestos fibres in mines and mills
}

\author{
C-Y HWANG
}

From the Department of Epidemiology and Health, Faculty of Medicine, McGill University, Montreal, Canada H3A $2 B 4$

\begin{abstract}
There is increasing evidence that fibre size and shape play an important part in the production of health effects related to asbestos. The dimensions of airborne fibres collected at various stages of fibre processing in three mines and six mills producing three types of asbestos were measured using phase contrast light microscopy and transmission electron microscopy. Airborne fibres of different asbestos types had appreciably different size and shape distributions. For a given asbestos type, fibres collected at different stages of processing differed in their size distributions but the differences were considerably less than between fibre types. Most of the airborne fibres to which miners and millers were exposed were short and thin and thus respirable. The physical properties which best differentiated crocidolite fibres from other types of asbestos and which had higher values determined for crocidolite fibres than those obtained for the other types, were median aspect ratio and the proportion of long thin fibres-that is, fibres $\leqslant 0.2 \mu \mathrm{m}$ in diameter and $>5 \mu \mathrm{m}$ in length as the percentage of total fibres. The median true diameter of amosite fibres was about four and three times higher than the median true diameters of chrysotile and crocidolite fibres respectively. The median true length of amosite fibres was more than four and two times higher than the median true lengths of chrysotile and crocidolite fibres respectively. The observed differences in size and shape of airborne fibres have important implications for the setting of work environmental standards and in explaining differences in health risks associated with different types of fibre.
\end{abstract}

There is evidence that the physical characteristics of fibres play an important part in the production of health effects related to asbestos. Experimental studies using animals have indicated a relationship between fibre size and the development of mesothelioma, ${ }^{1-3}$ and fibres that are thin, or long but thin, have been reported to be the most carcinogenic. $^{2-4}$ The pronounced differences in the diameters of asbestos fibres from the Cape and Transvaal regions of South Africa have been suggested as an explanation for the difference in frequency of mesothelioma in workers in these two regions. ${ }^{45}$ The proportional death rates from mesothelioma in workers exposed to crocidolite or to mixed asbestos types are much higher than the rates in those exposed to chrysotile alone. ${ }^{6}$

The rationale supporting the hypothesis that the physical dimensions of fibres play an important part

Received 21 July 1982

Accepted 24 August 1982 in the occurrence of mesothelioma is good. ${ }^{7}$ The diameter of an airborne asbestos fibre essentially determines its settling rate, which is important for penetration and deposition within the lung. ${ }^{8}$ Length influences the chance of a fibre being deposited by interception while fibre curliness increases interception in the airways ${ }^{9}$ and, combined, these factors determine the size and shape of fibres that can enter and be deposited in the lung parenchyma. Here size and shape determine the ability of macrophages and other body protective mechanism to operate ${ }^{1011}$ and possibly influence the ability of fibres to reach the pleura or peritoneum. Although it is recognised that fibres deposited in the lung may be modified chemically or physically, or both, removed, or translocated, one of the more important factors in identifying the aetiology of asbestos related diseases is a knowledge of the materials to which workers are exposed.

The asbestos mining industry defines one large group of workers who are continuously exposed to 
asbestos. In Canada, a major chrysotile producing country, about 8400 persons were employed annually in the asbestos mines and mills and in South Africa, a major amphibole producing country, more than 15000 workers were employed in 1976 by industry producing crocidolite and amosite. ${ }^{12}$ The purpose of this present report is: (a) to describe the size and shape of airborne fibres collected at various stages of processing in the industry producing chrysotile, crocidolite, or amosite asbestos types; (b) to examine whether the size and shape of various asbestos types differ for the same stage of processing; and (c) to examine whether the size and shape of fibres differ to an extent that might explain differences in health experienced by miners and millers exposed to these three types of asbestos.

\section{Material and methods}

Samples of airborne dust were collected using Millipore membrane filters (type AA; $0.8 \mu \mathrm{m}$ pore size, $37 \mathrm{~mm}$ diameter). The samples were collected at an underground mine and two mills producing crocidolite in Cape Province, South Africa; an underground mine and three mills producing amosite in Transvaal, South Africa; and an open pit mine and a mill producing chrysotile in Quebec, Canada.

Size and shape of airborne fibres collected at the initial and final stages of fibre production were examined and measured using light optical microscopy and transmission electron microscopy (TEM). The following were measured for each fibre: (a) true diameter, which was the average width of the central portion of the fibre and $(b)$ true length, which was the length measured along the central line of the fibre. The aspect ratio of the fibre was calculated by dividing the TEM-measured true length by the true diameter. Only those particles with aspect ratios equal to or greater than three were defined as fibres. Fibre bundles or aggregates were considered as one fibre. The details of the methods of measurement have been reported elsewhere. ${ }^{7}$

\section{Results}

\section{GENERAL APPEARANCE}

\section{Crocidolite (figs 1a and 1b)}

With the exception that airborne fibres in the mining operations tended to be attached to non-fibrous particles more often than in the milling areas, the shape of fibres was generally similar. Single fibres were thin, straight, and slender with a symmetrical appearance. Many fibres showed square ends but few had triangular or needle-like ends. Some were electronmicroscopically transparent and others had

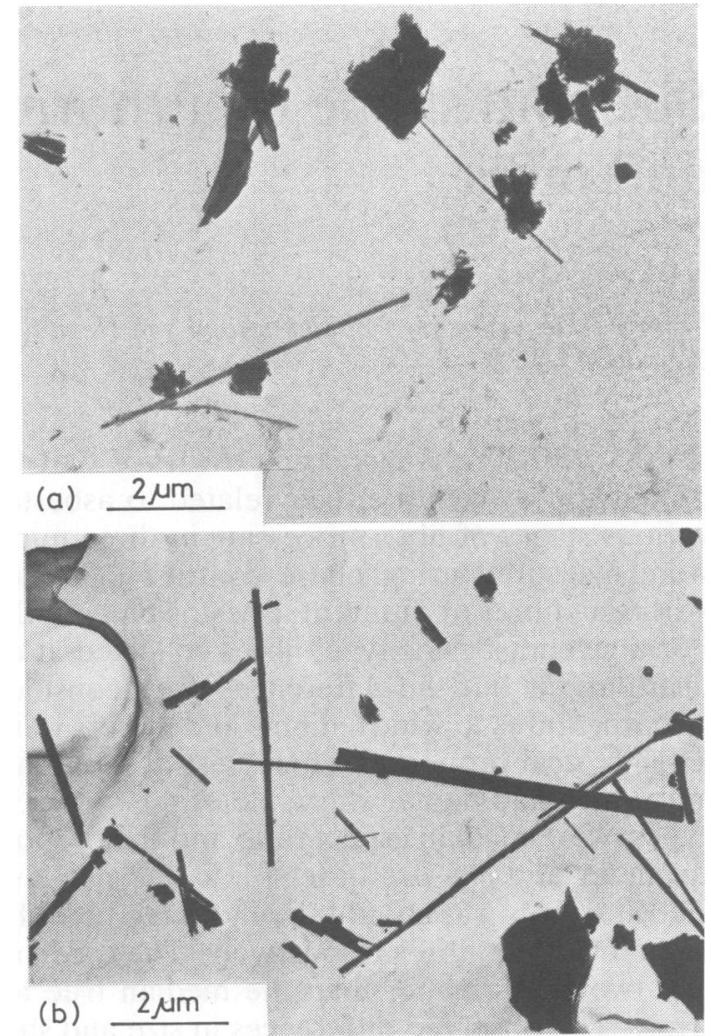

Fig 1 Electron micrographs of airborne asbestos fibres (a) in crocidolite mining area and (b) in crocidolite bagging area.

a noded appearance. Fibre bundles were occasionally seen with split ends; shorter bundles were straight but the long ones became slightly curved. Although rare, thin fibrils of crocidolite were seen to be very curly, these fibrils were probably deformed by the mechanical processing. Fibres also formed agglomerates.

Amosite (figs 2a and 2b)

Fibres collected in the underground mine were thinner and shorter than those from mills. Agglomerates of fine particles also appeared in the mining environments, occasionally attached to fibres. Amosite fibres in mills were thicker and longer than crocidolite from mills. As for crocidolite fibres, amosite fibres had in general a symmetrical and squareended appearance; some had triangular ends. Bundles of amosite fibres were rarely observed and fibres formed agglomerates occasionally.

Chrysotile (figs $3 \mathrm{a}$ and $3 \mathrm{~b}$ )

Fibres generated from drilling in the chrysotile open 


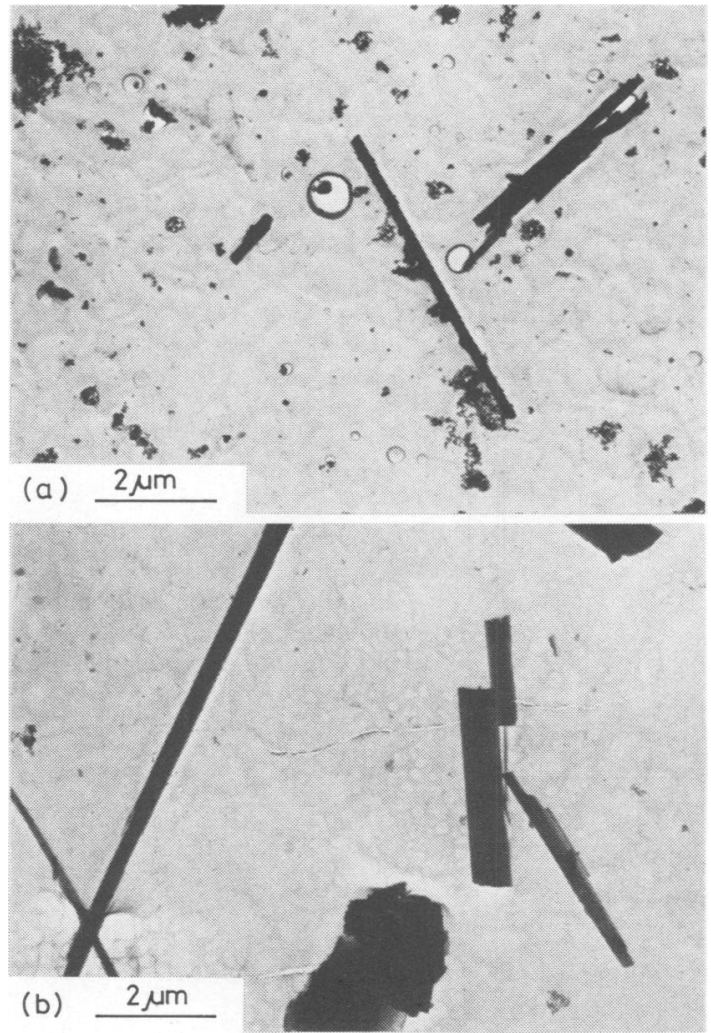

Fig 2 Electron micrographs of airborne asbestos fibres (a) in amosite mining area and (b) in amosite bagging area.

pit mine were numerous and appeared to be very fine (fig 3a). Most of the fine fibrils were short compared with fibres found in the crocidolite mine and the amosite mine. Many bundles about 5-10 $\mu \mathrm{m}$ in length were found with split ends. Non-fibrous particles with various sizes were also observed. In general, bundles of thin fibres as well as (fibre-particle) agglomerates were typical of airborne fibres collected in the chrysotile milling plant (fig 3b). Many bundles were long and curly, and their dimensions were difficult to measure. Single fibrils of chrysotile were straight and relatively symmetrical. Occasionally the single fibrils were observed to be attached side by side to other fibres which were shorter and thinner. The shape of fibre ends varied from fibre to fibre and from bundle to bundle. The hollow-core structures of chrysotile fibrils were occasionally observed.

\section{SIZE DISTRIBUTIONS OF AIRBORNE FIBRES}

True diameter and true length distributions of airborne fibres in the various stages of fibre processing

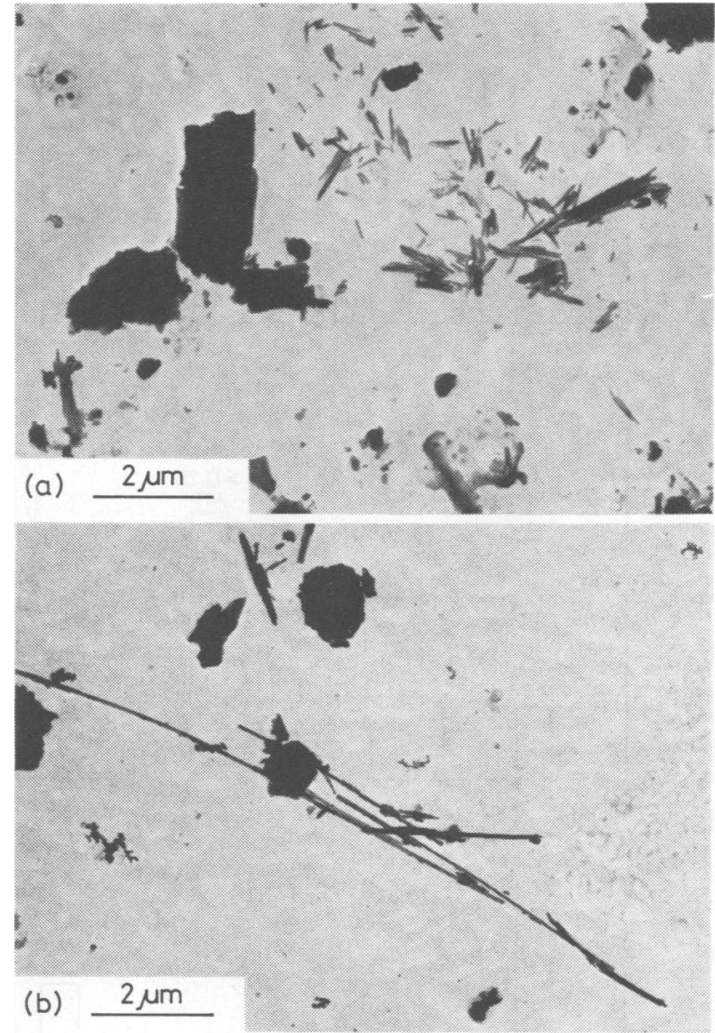

Fig 3 Electron micrographs of airborne asbestos fibres (a) in chrysotile mining area and (b) in chrysotile bagging area.

were non-Gaussian (figs 4 and 5). For the industry producing single asbestos type, airborne fibres collected at the initial processing stage (including mining operations such as drilling, shovelling, slushing, hammering, and tipping) and the final processing stage (bagging) differred in their size (diameter and length) distributions, but the differences between stages were considerably less than between asbestos types.

\section{DIAMETER}

The median true diameters of airborne crocidolite, amosite, and chrysotile fibres, as determined by transmission electron microscopy, were $0.07 \mu \mathrm{m}$ (initial stage) to $0.09 \mu \mathrm{m}$ (final stage), $0.20 \mu \mathrm{m}$ (initial) to $0.26 \mu \mathrm{m}$ (final), and $0.05 \mu \mathrm{m}$ (initial) to $0.06 \mu \mathrm{m}$ (final) respectively (table 1). According to median diameters, chrysotile fibres were thinnest while amosite fibres were thickest. The quartile range, defined as the difference between the third quartile and the first quartile of a size distribution, increased with increasing median true diameter 

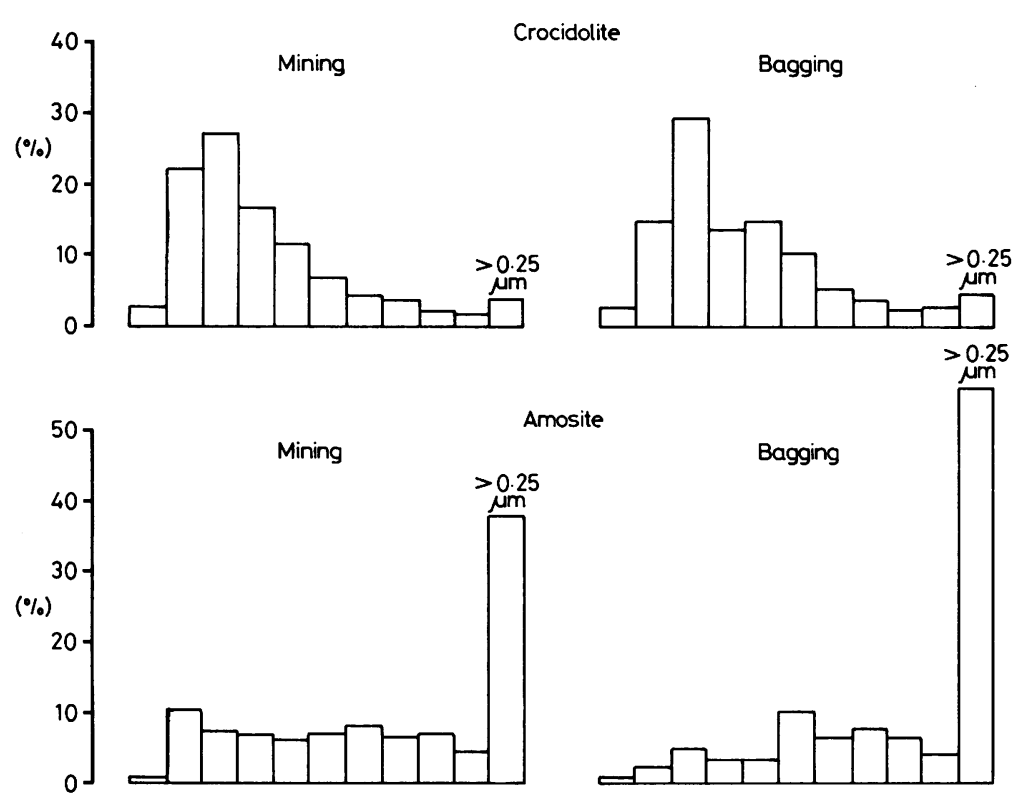

Fig 4 Percentage distribution diameters of crocidolite, amosite, and chrysotile fibres by stage of processing.

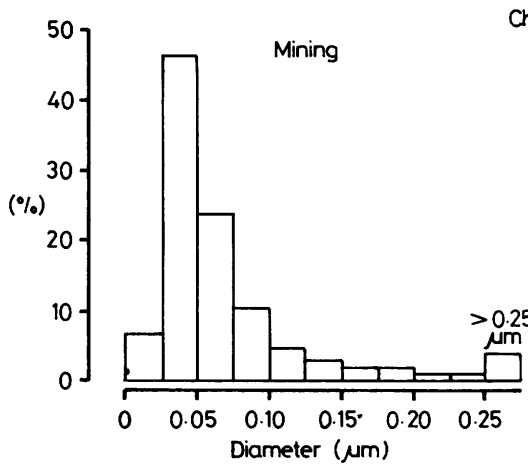

Chrysotile

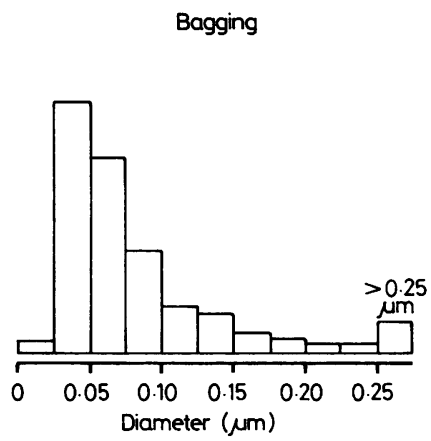

Table 1 Median true diameter and quartile range of true diameter distribution by stage of processing (as determined by transmission electron microscopy)

\begin{tabular}{|c|c|c|c|}
\hline Stage of asbestos processing & Fibres in crocidolite production & Fibres in amosite production & Fibres in chrysotile production \\
\hline $\begin{array}{l}\text { Initial: } \\
\text { Median true diameter }(\mu \mathrm{m}) \\
\text { Quartile range }(\mu \mathrm{m}) \\
\text { No of fibres }\end{array}$ & $\begin{array}{r}0.07 \\
0.06 \\
2779\end{array}$ & $\begin{array}{r}0.20 \\
0 \cdot 21 \\
802\end{array}$ & $\begin{array}{r}0.05 \\
0.04 \\
2269\end{array}$ \\
\hline $\begin{array}{l}\text { Final: } \\
\text { Median true diameter }(\mu \mathrm{m}) \\
\text { Quartile range }(\mu \mathrm{m}) \\
\text { No of fibres }\end{array}$ & $\begin{array}{r}0.09 \\
0.07 \\
1811\end{array}$ & $\begin{array}{r}0.26 \\
0.24 \\
2662\end{array}$ & $\begin{array}{r}0.06 \\
0.05 \\
3047\end{array}$ \\
\hline
\end{tabular}



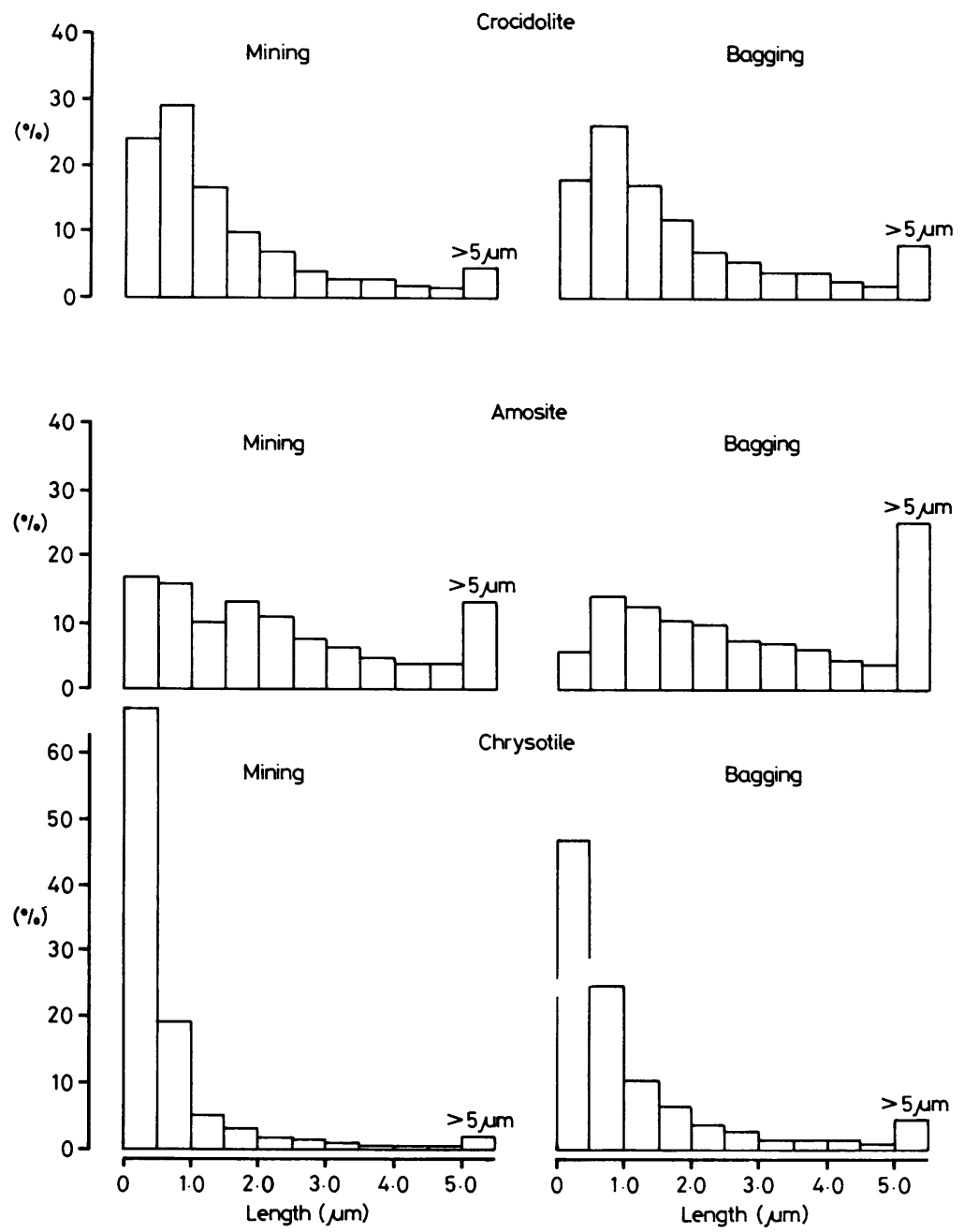

Fig 5 Overall length distributions of crocidolite, amosite, and chrysotile fibres by stage of processing.

(table 1).

The number of airborne fibres greater than $0.25 \mu \mathrm{m}$ in diameter as a percentage of the total number of fibres measured is highest $(55.4 \%)$ in the amosite bagging areas while the percentage of fibres in the chrysotile (or crocidolite) mining areas has the lowest value of $3.4 \%$ (fig 4 ). No airborne fibres had diameters greater than $3 \mu \mathrm{m}$.

\section{LENGTH}

Although fibre length is perhaps the most basic characteristic of fibres in relation to respirability, the measurement of the complete length distribution of airborne fibres is difficult because of the presence of electronmicroscopic specimen grids. The overall length distributions of fibres were determined by combining the results obtained by both phase contrast light microscopy and electron microscopy. ${ }^{7}$ The length distributions of the fibres visible electronmicroscopically and light optically differed slightly in mining and in bagging areas. The difference between the length distributions of the various fibre types was distinct: median lengths of crocidolite, amosite, and chrysotile in the mine were $0.95,1.83$, and $0.34 \mu \mathrm{m}$, respectively, and in the bagging area $1.16,2.53,0.55 \mu \mathrm{m}$, respectively (table 2 ). The quartile range increased with increasing median true length. The percentage of airborne fibres longer 
Table 2 Median true length and quartile range of the overall true length distribution by stage of processing

\begin{tabular}{llll}
\hline Stage of asbestos processing & Fibres in crocidolite production & Fibres in amosite production & Fibres in chrysotile production \\
\hline Initial: & & & \\
$\quad$ Median true length $(\mu \mathrm{m})$ & 0.95 & 1.83 & 0.34 \\
Quartile range $(\mu \mathrm{m})$ & 1.30 & 2.64 & 0.44 \\
Final: & & & \\
Median true length $(\mu \mathrm{m})$ & 1.16 & 2.53 & 0.55 \\
Quartile range $(\mu \mathrm{m})$ & 1.64 & 3.65 & 0.92 \\
\hline
\end{tabular}

than $5 \mu \mathrm{m}$ was highest $(24.5 \%)$ in the amosite bagging work environments; the percentage was lowest $(1.3 \%$ ) in the chrysotile mining areas (fig 5). Chrysotile fibres had an unusually high percentage of short fibres (under $5 \mu \mathrm{m}$ in length) as compared with amosite or crocidolite fibres (fig 5).

\section{ASPECT RATIO}

Table 3 shows the median aspect ratios of individual fibres (and bundles) collected at initial and final stages of processing as well as the fibres with aspect ratios greater than 40 as percentages of fibres

Table 3 Median aspect ratio and fibres with aspect ratios greater than 40 as a percentage of total number of fibres observed at the initial and final stages of processing (by transmission electron microscopy)

\begin{tabular}{|c|c|c|c|}
\hline \multirow{2}{*}{$\begin{array}{l}\text { Stage of processing } \\
\text { Initial: } \\
\text { Median aspect ratio } \\
\text { Percentage }\end{array}$} & \multicolumn{2}{|c|}{ Crocidolite Amosite } & \multirow{2}{*}{$\begin{array}{l}\text { Chrysotile } \\
6 \cdot 3 \\
2 \cdot 5\end{array}$} \\
\hline & $\begin{array}{r}11.7 \\
9.6\end{array}$ & $\begin{array}{l}8 \cdot 4 \\
2 \cdot 9\end{array}$ & \\
\hline $\begin{array}{l}\text { Final: } \\
\text { Median aspect ratio } \\
\text { Percentage }\end{array}$ & $\begin{array}{l}13.2 \\
11.5\end{array}$ & $\begin{array}{l}8.8 \\
5.1\end{array}$ & $\begin{array}{l}8.0 \\
4.7\end{array}$ \\
\hline
\end{tabular}

observed by transmission electron microscopy. At both the initial and final stages of processing, the median aspect ratios and the percentages of crocidolite fibres observed have higher values than that of amosite or chrysotile fibres observed. Fibres with aspect ratios over 400 have been observed in the chrysotile bagging areas.

Table 4 shows the fibres $>5 \mu \mathrm{m}$ in length and $\leqslant 0.2 \mu \mathrm{m}$ in diameter as a percentage of the total number of fibres observed for each process by transmission electron microscopy.

Table 4 Fibres $>5 \mu \mathrm{m}$ in length and $\leqslant 0.2 \mu \mathrm{m}$ in diameter as percentage of the total number of fibres observed for each process (by transmission electron microscopy)

\begin{tabular}{llll}
\hline Process & Crocidolite & Amosite & Chrysotile \\
\hline Mining & 3.02 & 2.23 & 0.34 \\
Bagging & 5.25 & 3.65 & 2.09 \\
\hline
\end{tabular}

\section{Discussion}

Most of the airborne fibres to which miners and millers were exposed were short and thin and thus respirable. Different dimensions of airborne fibres are associated with different processes, but the differences are less than that between fibre types. While amosite fibres are longer and thicker than other types of asbestos fibre, crocidolite fibres in air tend to be more slender than amosite or chrysotile fibres. No airborne fibres had diameters greater than $3 \mu \mathrm{m}$; hence on diameter gravitational deposition criteria alone, all fibres would be capable of penetrating deeply into the lung. Attachment of particles to fibres can increase the cross sectional area of individual fibres and thus alter their aerodynamic behaviour in the human respiratory system. Amosite fibres, which are longest and thickest are more likely to be deposited in the upper respiratory system owing to the mechanisms of interception and gravitational settlement.

Pooley and Clark showed that fibres detected in lung tissue are longer than airborne fibres. ${ }^{12}$ The chrysotile airborne fibres examined in the present study, however, are much shorter than those detected in the lung by Pooley and Clark. One of the most likely explanations might be that the clearance mechanisms of the lung operate more efficiently with shorter fibres. Evidence from animal experiments supports such an explanation. ${ }^{14}$ The size and shape of fibres may reduce the diffusion coefficient and affect the total lung deposition, thus the difference between the size distributions measured in the lung and those in the air may reflect the size selection of the fibre deposition mechanisms as well as that of the clearance mechanisms. ${ }^{15}$

The results of the dimensional measurements of the airborne fibres have implications for health effects and for carcinogenicity. Indications of the relative carcinogenicity of crocidolite, amosite, and chrysotile fibres have been obtained from epidemiological investigations and animal experiments. Crocidolite fibres, in particular, have been related to the production of mesothelioma. ${ }^{616-18}$ The physical properties which best differentiated crocidolite fibres from other asbestos types and 
which had higher values determined from crocidolite fibres than those obtained for the other types, were median aspect ratio of fibres (table 3 ) and the proportion of long thin fibres - that is, fibres with aspect ratios $>40$ as a percentage of the total number of fibres shown in table 3 or fibres $\leqslant 0.2 \mu \mathrm{m}$ in diameter and $>5 \mu \mathrm{m}$ in length as the percentage of the total number of fibres shown in table 4 .

If the dimension of asbestos fibres are important in the production of mesothelioma the aspect ratios and the percentages of such long but thin fibres could be the most significant properties. The possible existence of a specific fibre dimension likely to be more hazardous to health, in particular, to the production of mesothelioma, than other dimensions has been reported by St:inton and Wrench, ${ }^{1}$ Stanton et $a l^{3}$ and later, by Pott. ${ }^{19}$ Stanton $e$ al have related higher tumour rates in animals to implanted fibres with a diameter less than $0.25 \mu \mathrm{m}$ and with a length greater than $8 \mu \mathrm{m} .^{3}$ According to Pott, the carcinogenic potency of a fibre is related to its length, diameter, and, possibly, by its aspect ratio and there might be a dimensional category in which fibres have a higher carcinogenic potency (with a carcinogenic factor of 100) relative to the carcinogenic potency of fibres in the other dimensional categories (with carcinogenic factors less than 100). ${ }^{19}$

Considerable help from Drs R S J du Toit and GW Gibbs, who made arrangements to visit mines and mills for sampling, is appreciated. Dr G W Gibbs collected the air samples from South Africa. I thank Mr M Harrigan and Ms T Cohen for technical help in measuring fibres and Mrs Irene McCammon for typing the manuscript. I acknowledge the Institute of Occupational and Environmental Health of the Quebec Asbestos Mining Association for financial support of this research.

\section{References}

' Stanton MF, Wrench C. Mechanisms of mesothelioma induction with asbestos and fibrous glass. $J$ Natl Cancer Inst 1972;48:797-821.

${ }^{2}$ Wagner JC, Berry G, Timbrell V. Mesotheliomata in rats after inoculation with asbestos. $\mathrm{Br} J$ Cancer 1973;28:173-85.

${ }^{3}$ Stanton MF, Layard M, Tegeris A, Miller E, May M, Kent E.
Carcinogenicity of fibrous glass: pleural response in the rat in relation to fibre dimension. J Natl Cancer Inst 1977;58:587603.

4 Timbrell V. Physical factors as etiological mechanisms. In: Bogovski P, Gilson JC, Timbrell V, Wagner JC, eds. Biological effects of asbestos. Lyon: International Agency for Research on Cancer, 1973:295-303. (Publ No 8.)

s Timbrell V, Griffiths DM, Pooley FD. Possible biological importance of fibre diameters of South African amphiboles. Nature 1971;232:55-6.

- McDonald JC, McDonald AD. Epidemiology of mesothelioma from estimated incidence. Prev Med 1977;6:426-46.

' Hwang CY, Gibbs GW. The dimensions of airborne asbestos fibres-I. Crocidolite from Kuruman area, Cape Province, South Africa. Ann Occup Hyg 1981;24:23-41.

- Timbrell V. The inhalation of fibrous dusts. In: Biological effects of asbestos. Ann NY Acad Sci 1965;132:255-73.

- Timbrell V, Skidmore JW. The effect of shape on particle penetration and retention in animal lungs. In: Walton WH, ed. Inhaled particles III. Vol 1. Woking, Surrey: Unwin Brothers Ltd, 1971:49-56.

16 Morgan A, Talbot RJ, Holmes A. Significance of fibre length in the clearance of asbestos fibres from the lung. Br J Ind Med 1978;35:146-53.

"Allison AC. Experimental methods-cell and tissue culture: effects of asbestos particles on macrophages, mesothelial cells and fibroblasts. In: Bogovski P, Gilson JC, Timbrell V, Wagner JC, eds. Biological effects of asbestos. Lyon: International Agency for Research in Cancer, 1973:89-93. (Publ No 8.)

${ }_{12}$ Gibbs GW, du Toit RSJ. Environmental considerations in surveillance of asbestos miners and millers. Ann NY Acad Sci 1979;330:163-78.

${ }^{13}$ Pooley FD, Clark NJ. A comparison of fibre dimensions in chrysotile, crocidolite and amosite particles for samples of airborne dust and from post-mortem lung tissue specimens. In: Wagner JC, ed. Biological effects of mineral fibres. Vol 1. Lyon: International Agency for Research in Cancer, 1980:79-86. (Publ No 30.)

14 Wright GW, Kushner M. The influence of varying lengths of glass and asbestos fibres on tissue response in guinea pigs. In: Walton WH, ed. Inhaled particles IV. Part 2. Oxford: Pergamon Press, 1977:455-74.

${ }^{15} \mathrm{Knight} \mathbf{G}$. Differences between asbestos fibre size distributions in air and in the lung. Ann Occup Hyg 1982;25:109.

${ }^{16}$ Wagner JC, Sleggs CA, Marchand P. Diffuse pleural mesothelioma and asbestos exposure in the North Western Cape province. Br J Ind Med 1960;17:260-71.

17 Webster I. Malignancy in relation to crocidolite and amosite. In: Bogovski P, Gilson JC, Timbrell V, Wagner JC, eds. Biological effects of asbestos. Lyon: International Agency for Research in Cancer, 1973:195-8. (Publ No 8.)

${ }^{18}$ McDonald AD, McDonald JC. Mesothelioma after crocidolite exposure during gas mask manufacture. Environ Res 1978;17:340-6.

19 Pott F. Some aspects on the dosimetry of the carcinogenic potency of asbestos and other fibrous dusts. Staub-Reinhaltung der Luft 1978;38:486-90. 